\title{
De Novo Myelodysplastic Syndrome and Subsequent Diagnosis of Primary Solid Tumors: Evidence from the National Cancer Institute 2001-2011*
}

\author{
KITTY VICTORIA ${ }^{1}$ and ISAAC G. FREEDMAN ${ }^{2}$ \\ ${ }^{1}$ University of Vermont Medical Center, Burlington, VT, U.S.A.; \\ ${ }^{2}$ Yale School of Medicine, New Haven, CT, U.S.A.
}

\begin{abstract}
Background: To our knowledge there are no population-level studies on the association between nontreatment-related myelodysplastic syndrome (MDS) and subsequent primary solid tumors. Materials and Methods: Adult patients diagnosed with non-treatment-related MDS were selected from the SEER 18 database and the risk of subsequent primary solid tumor was calculated. Results: A total of 40,780 patients with a diagnosis of MDS were reported in the SEER 18 registry during 2001 to 2011. In these patients, 2,111 subsequent primary solid tumors were diagnosed with an observed/expected $(O / E)$ ratio of 1.16 and an absolute excess risk of 26.86 per 10,000. Diagnosis of subsequent solid tumor was most likely immediately after diagnosis of MDS or within 1 year of diagnosis. Conclusion: The risk of diagnosis of primary solid tumor malignancy in adult patients with de novo MDS is significantly higher compared to the general population. It is unclear whether this is due to detection bias or underlying pathophysiology.
\end{abstract}

Myelodysplastic syndromes (MDS), caused by derangements in hematopoiesis, may occur de novo, secondary to malignancy, as treatment-related MDS or because of exposure to certain toxins. Presentations range from indolent disease to transfusion-

Both Authors contributed equally to this work.

*Preliminary abstract presented at the 2016 International Journal of Clinical Oncology, Coeur d'Alene, ID, U.S.A.

Preliminary abstract published in the journal Anticancer Research 36: 6705-6716, Abstract 10 page 6711, 2016.

Correspondence to: Isaac G. Freedman, MPH, Yale School of Medicine, 330 Cedar St., New Haven, CT 06510, U.S.A. Tel: +1 6106086420, e-mail: isaac.freedman@yale.edu

Key Words: Primary myelodysplastic syndrome, risk of second malignancy, SEER database, de novo myelodysplastic syndrome, primary solid tumors. dependent disease and conversion to acute leukemia. MDS is a disease primarily of the elderly (1), thus its prevalence is thought to be increasing. Recent analysis estimated the incidence at 103 per 100,000 in the population aged 65 years and older (2). Thus, MDS represents a large economic burden, especially in patients requiring frequent supportive therapies (3).

The diagnosis of MDS relies primarily on cytological and histological evaluation of peripheral blood and bone marrow in addition to high clinical suspicion. There are two major classification systems primarily in use: French-AmericanBritish (FAB) classification (4) and the more recently updated World Health Organization (WHO) classification (5). The WHO classification differs from the FAB in that it accounts for genetic abnormalities $\operatorname{del}(5 \mathrm{q})$ and splicing factor 3 b subunit 1 (5). Recent studies have implicated mutations in gene splicing mechanisms and epigenetic regulators as important prognostic indicators, although not yet included in any classification systems $(6,7)$.

In an analysis published in the 1992 by Sans-Sabrafen et al., 155 patients with a known diagnosis of primary MDS had a significantly higher incidence of tumors than the general population, 21 of them presenting with malignant solid tumors (8). An additional case study of six patients with primary MDS and an additional second primary malignancy revealed all six with a normalization of cytopenia post treatment of their co-existing malignancy (9).

MDS became reportable to the Surveillance, Epidemiology, and End Results (SEER) Program (the United States cancer surveillance program) in 2001. This database represents approximately $26 \%$ of the US population including nine states (New Mexico, Hawaii, Utah, Iowa, Connecticut, Greater California, Kentucky, Louisiana, New Jersey), five metropolitan areas, and the Alaska Native Tumor Registry. A study published in 2007 based on the SEER 17 data from 2001 to 2003 investigating incidence and survival of patients with MDS in the United States, found more than 10,000 cases diagnosed annually, with the 3 -year survival rate at about $35 \%$ (10). To our knowledge, there have been no population- 
based studies investigating the association between de novo MDS and incidence of solid tumors.

\section{Materials and Methods}

Population. Data for adult patients diagnosed with non-treatmentrelated MDS were retrieved from the SEER 18 database. The term "myelodysplastic syndrome and other myeloproliferative" in the International Classification of Childhood Cancer (ICCC) site recode extended ICD-O-3/WHO 2008 (2010 updates to the leukemia and lymphoma codes in the SEER database) and found 57,548 cases. The ICCC-3 classifies tumors into 12 main diagnostic groups with 47 subheadings. These categories are designed to be consistent with the genetic and pathological categorizations of the WHO (11-14). This classification applies the codes, rules and morphology of the ICD-0-3 and is continuous with previous classifications (14). ICCC3 also includes previously excluded subgroups including group $1 \mathrm{~d}$, 'myelodysplastic and other myeloproliferative disorders', rarely found in children, included, however, for the benefit of populationbased studies and databases.

The WHO published its recommendations for the classification of MDS in 2016 (5). The WHO's recommendations classify MDS into i) MDS with single lineage dysplasia, ii), MDS with multilineage dysplasia iii) MDS with ringed sideroblasts (single or multilineage dysplasia, iv) MDS with isolated 5q deletion, v) MDS with excess blasts-1 or 2, vi) MDS unclassified.

Data analysis. The SEER database was queried for total and primary MDS cases from 2001-2011. Rate, frequency and life expectancy of primary MDS were identified for all patients diagnosed with MDS, totaling 115,096 patients and these were stratified by race and sex. Out of the total, 40,780 cases were analyzed for development of primary solid tumor (PST) and included only cases that were primary diagnoses, without a prior cancer diagnosis, thus therapy-related cases were excluded. The risk of malignant PST was calculated in these patients using a primary standardized incidence ratio (MP-SIR) analysis in the SEER Stat software (Surveillance Research Program, National Cancer Institute SEER STAT software, seer.cancer.gov/seerstat version 8.3.2). Due to the multiplicity of solid tumor categories in the SEER database (119 types), a confidence level of $\alpha=0.001$ was used to reduce the possibility of false positives from a multiple comparisons problem. The observed/expected $(\mathrm{O} / \mathrm{E})$ ratio and confidence intervals $(\mathrm{CI})$ organized by solid tumor location, namely esophagus, ascending colon, liver, lung/bronchus, urinary system, kidney, kidney/renal pelvis, colon/rectum/anus, respiratory system, digestive system and urinary system. These tumor subtypes were organized by latency from time of MDS diagnosis. Latency of 0 months was taken as synonymous with the simultaneous diagnosis of MDS and PST. The latency periods of $0,1-5,6-11,12-59$ and $>60$ months were calculated for differences in $\mathrm{O} / \mathrm{E}$ ratio, subcategorized by tumor location. The data were stratified by sex, age at diagnosis, race and absolute excess risk (AER) per 10,000 population. The AER is an absolute measurement which correlates to the excess cancer events.

\section{Results}

A total of 115,096 patients with 'myelodysplastic syndrome and other myeloproliferative diseases' and 40,780 patients
Table I. Demographics of patients diagnosed with primary solid tumor (PST) subsequent to diagnosis of myelodysplastic syndrome (MDS).

\begin{tabular}{lc}
\hline & Value \\
\hline Total number of patients with MDS in cohort & 40,780 \\
Gender, n (\%) & \\
Male & $22,453(55.1 \%)$ \\
Female & $18,327(44.9 \%)$ \\
Race, n (\%) & \\
White & $34,151(83.7 \%)$ \\
Black & $3,203(7.9 \%)$ \\
Other & $2,840(7.0 \%)$ \\
Total number of PST & 2,111 \\
Gender, n (\%) & \\
Male & $1,297(61.4 \%)$ \\
Female & $814(38.6 \%)$ \\
Age at diagnosis of PST & $76.37(0-98)$ \\
Median (range) & \\
\hline
\end{tabular}

with MDS as a primary diagnosis were reported in the SEER 18 registry from 2001 to 2011. Demographics of the population by gender and race are shown in Table I. The racial profile of the MDS cohort consisted of $83.74 \%$ White, $7.85 \%$ Black and $6.96 \%$ other. In this population, a total of 2,111 primary solid tumors were diagnosed with a total O/E ratio of 1.16 , and an absolute excess risk of 26.86 per 10,000 (95\% CI $=1.07-1.24, p<0.0001)$. Out of 94 possible regions of origin for solid tumors, 13 were associated with prior diagnosis of MDS at the $p<0.10$ level, spanning primary solid tumor locations in the digestive system, esophagus, ascending colon, liver and biliary system, respiratory system, male genital system, prostate, urinary system, and kidney (Table II). At the $p<0.001$ level, solid tumors of the digestive system, malignancies of the liver, gallbladder, intrahepatic bile duct and other biliary organs; liver alone; respiratory system, lung, bronchus, trachea, mediastinum and other respiratory organs; lung and bronchus; kidney and renal pelvis; and kidney alone were significantly more likely after a diagnosis of MDS (Table II). The mean age at diagnosis of MDS was 76.37 years (0-98 years) and mean follow up duration of patients was 15.80 months $(0-120+$ months $)$.

PST and latency period. Patients were significantly more likely to be diagnosed with PST simultaneously with MDS (O/E 2.3) or within 11 months (O/E 1.22). The latency periods from 1 to 10 years from the diagnosis of MDS did not show any statistically significant increase in observed versus expected diagnosis of PST SPM of any origin. PST SPMs originating in the colon and rectum were more common than expected in 0-0 and 1-5 month time periods, but not overall. Likewise, tumors originating in the stomach were more common than expected in the first 1-5 months, but not at any 
Table II. Risk of diagnosis of primary solid tumor (PST) subsequent to diagnosis of myelodysplastic syndrome (MDS) by patient sex and solid tumor location.

\begin{tabular}{|c|c|c|c|c|c|}
\hline \multirow[b]{2}{*}{ Event Type } & \multirow[b]{2}{*}{$\mathrm{O} / \mathrm{E}$} & \multicolumn{2}{|c|}{$95 \% \mathrm{CI}$} & \multirow[b]{2}{*}{$p$-Value } & \multirow[b]{2}{*}{ AER } \\
\hline & & Lower & Upper & & \\
\hline \multicolumn{6}{|l|}{ All Solid Tumors } \\
\hline Total & 1.16 & 1.07 & 1.24 & 0.0001 & 26.86 \\
\hline Male & 1.19 & 1.06 & 1.33 & 0.0027 & 28.34 \\
\hline Female & 1.14 & 1.03 & 1.24 & 0.0057 & 25.27 \\
\hline Digestive system & 1.34 & 1.17 & 1.53 & $<0.0001$ & 14.39 \\
\hline Esophagus & 1.74 & 0.99 & 2.81 & 0.0371 & 1.68 \\
\hline Ascending colon & 1.63 & 1.03 & 2.44 & 0.0262 & 2.23 \\
\hline Liver, gallbladder, intrahep bile duct and other biliary & 2.29 & 1.65 & 3.08 & $<0.0001$ & 6.17 \\
\hline Liver & 3.13 & 2.16 & 4.38 & $<0.0001$ & 5.78 \\
\hline Respiratory system & 1.41 & 1.22 & 1.63 & $<0.0001$ & 13.97 \\
\hline Lung, bronchus, trachea, mediastinum and other respiratory organs & 1.43 & 1.23 & 1.66 & $<0.0001$ & 13.77 \\
\hline Lung and bronchus & 1.43 & 1.23 & 1.66 & $<0.0001$ & 13.81 \\
\hline Male genital system & 0.8 & 0.65 & 0.97 & 0.0286 & -6.37 \\
\hline Prostate & 0.8 & 0.65 & 0.98 & 0.0329 & -6.27 \\
\hline Urinary system & 1.22 & 0.99 & 1.49 & 0.0562 & 4.48 \\
\hline Kidney and renal pelvis & 1.72 & 1.23 & 2.33 & 0.0009 & 4.3 \\
\hline Kidney & 1.81 & 1.29 & 2.48 & 0.0004 & 4.41 \\
\hline
\end{tabular}

AER, Absolute excess risk calculated as cancers per 10,000 person-years.

other time. However, several tumor sites were more common than expected, both overall and in the first 6 months, including tumors of the digestive system; kidney; kidney and renal pelvis; liver; lung; lung, bronchus, trachea, mediastinum, and other respiratory organs; respiratory system; male genital system; and prostate. Notably, tumors originating in the liver were more common than expected from 0-119 months postMDS diagnosis and tumors of the lung and bronchus were more common 0-59 months post-MDS diagnosis.

PST and sex. Our MDS cohort, totaling 40,780 individuals, consisted of $55.06 \%$ males and $44.94 \%$ females. Out of the total 2,111 cases of non-treatment related MDS diagnosed with PST, 1,297 were male and 814 were female. Diagnosis of any PST was significantly more likely in men and women simultaneously with ( 0 months latency) or within 6 months of (0-5 month latency) diagnosis of MDS. Females were diagnosed with more PSTs originating from any solid organ than expected, relative to Males (O/E 1.19 versus 1.14). Specifically, Female individuals had higher than expected diagnoses of solid tumors, relative to Male individuals, originating in the digestive system, kidney, kidney and renal pelvis, liver, and urinary system, while Males had higher than expected diagnoses of PSTs in the esophagus; esophagus; liver, gallbladder, intrahepatic bile duct and other biliary organs; lung, lung and bronchus, and lung, bronchus, trachea, mediastinum and other respiratory organs; respiratory system; and, of course, in the male genital system and prostate.
PST and age/sex. Our findings concurred with the findings of previous studies $(1,2,8,10)$. The elderly population had a higher incidence of MDS, with the majority of cases occurring in the $60+$ age group, mean age of diagnosis at 75 years (Tables I and II). The rate of MDS was higher in males from all age distributions, with the $85+$ category having the largest differential (M: rate 98.43, F: rate 44.48). The incidence of MDS by age and gender scales roughly exponentially, with a small peak at 1-4 years old (113 cases; 62 cases M, 51 cases F) followed by an exponential increase from 64 cases ( 31 cases M, 33 cases F) in the 5-9 years-old age range, reaching a peak at the $85+$ age range with 8,910 cases (4,521 cases M, 4,398 cases F). Of all cases, $18.9 \%$ were reported in individuals less than 65 years old and $81.1 \%$ were reported in individuals 65 years of age or older.

Bias. Although we were able to control for age, sex, race and prior history of chemotherapy, due to limitations in reporting in the SEER database, we were unable to control for other known risks for MDS such as exposure to benzene, smoking, and obesity (13).

\section{Discussion}

Previous studies of smaller scale have indicated a higher incidence of malignant tumors in patients with MDS (8), however, to our knowledge this is the first population-based study to evaluate the incidence of diagnosis of solid tumors in patients with a primary diagnosis of MDS in the United 
States. Our findings of the MDS cohort correlated with previous population-based studies showing that the incidence of MDS increases with advanced age $(10,15)$, with the majority aged over 60 years, with highest incidence in patients over 75 years old, and is greatest in White males.

An interesting difference from previously published SEER database studies is the higher rates of MDS found in both males and females. One explanation could be the more recent classification system of the ICCC-3 which incorporates a broader definition and may be including populations which had been missed with the ICD-03 coding system.

In a 2007 study based on the SEER 17 registry, patients diagnosed with MDS from 2001-2003, 998 out of 7131 (14\%) were found to have had other primary tumors diagnosed prior to MDS diagnosis, with the most common solid tumor sites being the prostate $(19.9 \%)$ and breast $(16.5 \%)$. There was a median time from diagnosis of first to second primary tumor of 4.5 years (10). Those findings contrast with our study, which found the greatest incidence of solid tumors to be simultaneously with diagnosis of MDS, with prostate having an $\mathrm{O} / \mathrm{E}$ ratio of $0.8(p<0.001,95 \% \mathrm{CI}=0.65-0.98, \mathrm{AER}=-0.627)$. This outlines the difference between patients with a known diagnosis of a PST who later develop primary MDS from patients with known MDS who then are diagnosed with a PST.

As breast and prostate cancer are of high prevalence and incidence in the general population, the finding is less likely to be causally related to de novo MDS, itself. It is possible that as patients are diagnosed and treated for a PST, their anemia could be either directly or indirectly related to the tumor itself or to the treatment for the tumor, rather than the suspicion of primary MDS, therefore accounting for the prolonged latency period. Malignancies of the liver and kidney were the most significantly noted for being diagnosed with MDS. Females had a much higher $\mathrm{O} / \mathrm{E}$ ratio of kidney and liver cancer than males, with the highest at the 0 -month latency. The reason for this difference is not known. One explanation for this dramatically higher incidence of diagnosis of PST immediately after or simultaneously with diagnosis of de novo MDS is detection bias. Undoubtedly, individuals who receive a primary malignant diagnosis are more likely to receive additional testing that may reveal a second diagnosis.

In an intriguing study of 131 patients who developed MDS or leukemia after treatment for a PST, there was no time difference noted in relationship to whether the patient had surgery alone or use of chemotherapy to the development of MDS or leukemia. The cytogenetic risk distribution was similar for the patients treated with chemotherapy or chemotherapy/radiation compared with patients who had surgery alone (15). From this observation, we postulate a potential causal association between MDS and the development of PST may be one of cytogenetic risk, rather than chemotherapy-induced mutations or a paraneoplastic etiology. This could explain the outcome in the previously mentioned case series of six patients in whom cytological abnormalities resolved after treatment for PST (9).

Recently, mutations affecting components of the spliceosome have been identified to be involved in both MDS and PST. In a study of 582 samples from patients with a myeloid malignancy, 209 were found to have identifiable spliceosome mutations, the highest percentage being in the group with refractory anemia and ringed sideroblasts (86\%) (16). MDS spliceosome mutations have been identified in patients with tumors of the breast (17-19), lung (20) and pancreas (21).

Further studies are needed to understand the etiology of these associations and even more importantly, their implication in screening and treatment. A genomic study of patients with treatment-related acute myeloid leukemia (AML) and MDS found that a history of chemotherapy may not in fact cause related mutations. In that study, the same percentage of mutations were found in patients with de novo and treatment-related AML. The same TP53 mutations present in patients with treatment-related AML and MDS were present in samples prior to chemotherapy (22).

Looking forward, our population-level study may assist in understanding the biological relationship between MDS and PST, may inform screening protocols for identifying higher-risk populations, and may inspire further studies for the identification of novel cytogenetic markers of both MDS and PST.

\section{References}

1 Rollison DE, Howlader N, Smith MT, Strom SS, Merritt WD, Ries LA, Edwards BK and List AF: Epidemiology of myelodysplastic syndromes and chronic myeloproliferative disorders in the United States, 2001-2004, using data from the NAACCR and SEER programs. Blood 112: 45-52, 2008.

2 McQuilten ZK, Wood EM, Polizzotto MN, Campbell LJ, Wall M, Curtis DJ, Farrugia H, McNeil JJ and Sundararajan V: Underestimation of myelodysplastic syndrome incidence by cancer registries: Results from a population-based data linkage study. Cancer 120: 1686-1694, 2014.

3 Goldberg SL, Chen E, Sasane M, Paley C, Guo A and Laouri M: Economic impact on US Medicare of a new diagnosis of myelodysplastic syndromes and the incremental costs associated with blood transfusion need. Transfusion 52: 2131-2138, 2012.

4 Bennett JM, Catovsky D, Daniel MT, Flandrin G, Galton DA, Gralnick HR and Sultan C: Proposals for the classification of the myelodysplastic syndromes. Br J Haematol 51: 189-199, 1982.

5 Arber DA, Orazi A, Hasserjian R, Thiele J, Borowitz MJ, Le Beau MM, Bloomfield CD, Cazzola M and Vardiman JW: The 2016 revision to the World Health Organization classification of myeloid neoplasms and acute leukemia. Blood 127: 2391-2405, 2016.

6 Kim E, Ilagan JO, Liang Y, Daubner GM, Lee SC, Ramakrishnan A, Li Y, Chung YR, Micol JB, Murphy ME, Cho H, Kim MK, Zebari AS, Aumann S, Park CY, Buonamici S, Smith PG, Deeg HJ, Lobry C, Aifantis I, Modis Y, Allain FH, Halene S, Bradley RK and Abdel-Wahab O: SRSF2 mutations contribute to myelodysplasia by mutant-specific effects on exon recognition. Cancer Cell 27: 617-630, 2015. 
7 Aslan D, Garde C, Nygaard MK, Helbo AS, Dimopoulos K, Hansen JW, Severinsen MT, Treppendahl MB, Sjo LD, Gronbaek K and Kristensen LS: Tumor suppressor microRNAs are downregulated in myelodysplastic syndrome with spliceosome mutations. Oncotarget 7: 9951-9963, 2016.

8 Sans-Sabrafen J, Buxo-Costa J, Woessner S, Florensa L, Besses C, Malats N and Porta M: Myelodysplastic syndromes and malignant solid tumors: analysis of 21 cases. Am J Hematol 41: 1-4, 1992.

9 Aznab M and Kavianymoghadam K: Secondary myelodysplastic syndrome may happen same as paraneoplastic syndrome in a period of time and prior to the appearance of malignancy: A case study of 6 patients. Int J Hematol Oncol Stem Cell Res 7: 30-34, 2013.

$10 \mathrm{Ma}$ X, Does M, Raza A and Mayne ST: Myelodysplastic syndromes: incidence and survival in the United States. Cancer 109: 1536-1542, 2007.

11 Kleihues P, Louis DN, Scheithauer BW, Rorke LB, Reifenberger G, Burger PC and Cavenee WK: The WHO classification of tumors of the nervous system. J Neuropathol Exp Neurol 61: 215-225; discussion 226-229, 2002.

12 Hamilton SR and Aaltonen AL: World Health Organization Classification of Tumours. Pathology and Genetics of Tumours of the Digestive System. Lyon, France, IARC Press, 2000.

13 Percy C, O'Conor G, Ries LG and Jaffe ES: Non-Hodgkin's lymphomas. Application of the International Classification of Diseases for Oncology (ICD-O) to the Working Formulation. Cancer 54: 1435-1438, 1984.

14 Fritz A PC, Jack A, Kanagaratnam S, Leslie S, Parkin DM and Whelan S: International Classification of Diseases for Oncology, ICD-0 (ed 3rd). Geneva, World Health Organization, 2013.

15 Abdelhameed A, Pond GR, Mitsakakis N, Brandwein J, Chun K, Gupta V, Kamel-Reid S, Lipton JH, Minden MD, Schimmer A, Shuh A, Yee K and Messner HA: Outcome of patients who develop acute leukemia or myelodysplasia as a second malignancy after solid tumors treated surgically or with strategies that include chemotherapy and/or radiation. Cancer 112: 1513-1521, 2008.

16 Scott LM and Rebel VI: Acquired mutations that affect premRNA splicing in hematologic malignancies and solid tumors. J Natl Cancer Inst 105: 1540-1549, 2013.

17 Ellis MJ, Ding L, Shen D, Luo J, Suman VJ, Wallis JW, Van Tine BA, Hoog J, Goiffon RJ, Goldstein TC, Ng S, Lin L, Crowder R, Snider J, Ballman K, Weber J, Chen K, Koboldt DC, Kandoth C, Schierding WS, McMichael JF, Miller CA, Lu C, Harris CC, McLellan MD, Wendl MC, DeSchryver K, Allred DC, Esserman L, Unzeitig G, Margenthaler J, Babiera GV, Marcom PK, Guenther JM, Leitch M, Hunt K, Olson J, Tao Y, Maher CA, Fulton LL, Fulton RS, Harrison M, Oberkfell B, Du F, Demeter R, Vickery TL, Elhammali A, Piwnica-Worms H, McDonald S, Watson M, Dooling DJ, Ota D, Chang LW, Bose R, Ley TJ, Piwnica-Worms D, Stuart JM, Wilson RK and Mardis ER: Whole-genome analysis informs breast cancer response to aromatase inhibition. Nature 486: 353-360, 2012.

18 Stephens PJ, Tarpey PS, Davies H, Van Loo P, Greenman C, Wedge DC, Nik-Zainal S, Martin S, Varela I, Bignell GR, Yates LR, Papaemmanuil E, Beare D, Butler A, Cheverton A, Gamble J, Hinton J, Jia M, Jayakumar A, Jones D, Latimer C, Lau KW, McLaren S, McBride DJ, Menzies A, Mudie L, Raine K, Rad R, Chapman MS, Teague J, Easton D, Langerød A; Oslo Breast Cancer Consortium (OSBREAC), Lee MT, Shen CY, Tee BT, Huimin BW, Broeks A, Vargas AC, Turashvili G, Martens J, Fatima A, Miron P, Chin SF, Thomas G, Boyault S, Mariani O, Lakhani SR, van de Vijver M, van't Veer L, Foekens J, Desmedt
C, Sotiriou C, Tutt A, Caldas C, Reis-Filho JS, Aparicio SA, Salomon AV, Børresen-Dale AL, Richardson AL, Campbell PJ, Futreal PA and Stratton MR: The landscape of cancer genes and mutational processes in breast cancer. Nature 486: 400-404, 2012.

19 Banerji S, Cibulskis K, Rangel-Escareno C, Brown KK, Carter SL, Frederick AM, Lawrence MS, Sivachenko AY, Sougnez C, Zou L, Cortes ML, Fernandez-Lopez JC, Peng S, Ardlie KG, Auclair D, Bautista-Piña V, Duke F, Francis J, Jung J, Maffuz-Aziz A, Onofrio RC, Parkin M, Pho NH, Quintanar-Jurado V, Ramos AH, RebollarVega R, Rodriguez-Cuevas S, Romero-Cordoba SL, Schumacher SE, Stransky N, Thompson KM, Uribe-Figueroa L, Baselga J, Beroukhim R, Polyak K, Sgroi DC, Richardson AL, JimenezSanchez G, Lander ES, Gabriel SB, Garraway LA, Golub TR, Melendez-Zajgla J, Toker A, Getz G, Hidalgo-Miranda A and Meyerson M: Sequence analysis of mutations and translocations across breast cancer subtypes. Nature 486: 405-409, 2012.

20 Imielinski M, Berger AH, Hammerman PS, Hernandez B, Pugh TJ, Hodis E, Cho J, Suh J, Capelletti M, Sivachenko A, Sougnez C, Auclair D, Lawrence MS, Stojanov P, Cibulskis K, Choi K, de Waal L, Sharifnia T, Brooks A, Greulich H, Banerji S, Zander T, Seidel D, Leenders F, Ansén S, Ludwig C, Engel-Riedel W, Stoelben E, Wolf J, Goparju C, Thompson K, Winckler W, Kwiatkowski D, Johnson BE, Jänne PA, Miller VA, Pao W, Travis WD, Pass HI, Gabriel SB, Lander ES, Thomas RK, Garraway LA, Getz G and Meyerson M: Mapping the hallmarks of lung adenocarcinoma with massively parallel sequencing. Cell 150: 1107-1120, 2012.

21 Biankin AV, Waddell N, Kassahn KS, Gingras MC, Muthuswamy LB, Johns AL, Miller DK, Wilson PJ, Patch AM, Wu J, Chang DK, Cowley MJ, Gardiner BB, Song S, Harliwong I, Idrisoglu S, Nourse C, Nourbakhsh E, Manning S, Wani S, Gongora M, Pajic M, Scarlett CJ, Gill AJ, Pinho AV, Rooman I, Anderson M, Holmes O, Leonard C, Taylor D, Wood S, Xu Q, Nones K, Fink JL, Christ A, Bruxner T, Cloonan N, Kolle G, Newell F, Pinese M, Mead RS, Humphris JL, Kaplan W, Jones MD, Colvin EK, Nagrial AM, Humphrey ES, Chou A, Chin VT, Chantrill LA, Mawson A, Samra JS, Kench JG, Lovell JA, Daly RJ, Merrett ND, Toon C, Epari K, Nguyen NQ, Barbour A, Zeps N; Australian Pancreatic Cancer Genome Initiative, Kakkar N, Zhao F, Wu YQ, Wang M, Muzny DM, Fisher WE, Brunicardi FC, Hodges SE, Reid JG, Drummond J, Chang K, Han Y, Lewis LR, Dinh H, Buhay CJ, Beck T, Timms L, Sam M, Begley K, Brown A, Pai D, Panchal A, Buchner N, De Borja R, Denroche RE, Yung CK, Serra S, Onetto N, Mukhopadhyay D, Tsao MS, Shaw PA, Petersen GM, Gallinger S, Hruban RH, Maitra A, Iacobuzio-Donahue CA, Schulick RD, Wolfgang CL, Morgan RA, Lawlor RT, Capelli P, Corbo V, Scardoni M, Tortora G, Tempero MA, Mann KM, Jenkins NA, Perez-Mancera PA, Adams DJ, Largaespada DA, Wessels LF, Rust AG, Stein LD, Tuveson DA, Copeland NG, Musgrove EA, Scarpa A, Eshleman JR, Hudson TJ, Sutherland RL, Wheeler DA, Pearson JV, McPherson JD, Gibbs RA and Grimmond SM: Pancreatic cancer genomes reveal aberrations in axon guidance pathway genes. Nature 491: 399-405, 2012.

22 Cogle CR, Craig BM, Rollison DE and List AF: Incidence of the myelodysplastic syndromes using a novel claims-based algorithm: high number of uncaptured cases by cancer registries. Blood 117: 7121-7125, 2011.

Received February 27, 2018 Revised August 23, 2018 Accepted August 30, 2018 